\title{
Study on the Prevalence of Trypanosoma Species Causing Bovine Trypanosomosis in South Achefer District, Northern Ethiopia
}

\author{
Endalew Debas*, Gedamu Mequannt \\ Hawassa University School of Veterinary Medicine
}

*Corresponding Author: Endalew Debas, Hawassa University School of Veterinary Medicine

\begin{abstract}
A cross sectional study was carried out From November, 2013 to February, 2014 at south Achefer district, Northern Ethiopia geographically it is located at $11^{\circ} 50^{\prime} \mathrm{N}$ latitude and $37^{\circ} 10^{\prime} \mathrm{E}$ longitude, $502 \mathrm{Km}$ away from Addis Ababa, the capital of Ethiopia. The study was carried on 420 indigenous cattle managed under small holder mixed crop-livestock Production system to determine the prevalence of bovine trypanosomosis. This study employs parasitological survey by the use of buffy coat examination and hematological study by the use of packed cell volume (PCV) to investigate the prevalence of trypanosome infection and the species of trypanosome affecting cattle in three villages of South Achefer district in Amhara regional state. Blood examination conducted on 420 randomly selected cattle showed an overall prevalence of 6.19\% without significant difference $(P>0.05)$ between the villages, sex and age, But the prevalence of trypanosome infection was shown to be significantly associated $(P<0.05)$ with BCS,PCV.and color The species of trypanosomes encountered in the current study were $T$ vivax and $T$ congolensewhich accounted for $62.5 \%$ and $31.25 \%$ of the overall infection, respectively. The prevalence of trypanosome infection did not show significant variation between cattle of different age groups and sexes $(P>0.05$ in each case). There was a significant $(P<0.05)$ association between trypanosome infection and body condition score $(B C S)$ of the study animals. The mean packed cell volume $(P C V)$ of trypanosome infected animals was significantly $(P$ $<0.05)$ lower than that of uninfected animals. Although the current study indicated low prevalence of trypanosome infection compared with previous studies, the significant impacts of trypanosomosis on cattle production and productivity should not be neglected. Entomological surveys are recommended in the future to generate a complete data on the epidemiology of the disease in the study area.
\end{abstract}

Keywords: Cattle, Ethiopia, prevalence, PCV, Trypanosomosis

\section{INTRODUCTION}

In Ethiopia, trypanosomosis is one of the major impediments to livestock development and agricultural production contributing negatively to the overall development in agriculture in general and to food self- reliance efforts of the nation in particular.While tsetse-bornetrypanosomosis is excluding some 180,000 to $200,000 \mathrm{~km}^{2}$ of agriculturally suitable landing the west and south west of the country, 14million heads of cattle,an equivalent number of small ruminants, nearly 7 million equines and 1.8million camels are at risk of contracting typanosomosis at any one time (Langridge, 1976 and MoARD, 2004).

Trypanosomosis is a complex disease caused by unicellular parasites Trypanosomes is found in the blood and other tissues of vertebrates including cattle and man (Uilenberg,1998). The diseases are caused by flagellate protozoa called trypanosomes, which are transmitted by a number of different arthropod vectors trypanosomes in various mammals (Aiello and Mays, 2005) and also biting flies may act as mechanical vectors, which requires only that blood containing infectious trypanosomes to be transferred from one animal to another but their significant in Africa is still undefined. In the case of T. vivax, Tabanus species and other biting flies seem to be the primary mechanical vectors (Aiello and Mays, 2005). The life cycle of trypanosome is complex in both tsetse fly vector and the mammalian host; trypanosomes undergo a series of transformations into different forms (Seifert, 1996).

Most tsetse-transmission is cyclical and begins when blood from a trypanosome infected animals are ingested by the fly. The trypanosome losses its surface coat, multiplies in the fly, then reacquire a surface coat and becomes infective. T. brucei species migrate from the gut to the proventriculus to the pharynx and eventually to the salivary glands. The cycle for $T$. congolense stops at the hypopharynx 
and the salivary glands are not invaded. The entire cycle for $T$. vivaxoccurs in the proboscis. The animal infective form in tsetse salivary gland is referred the metacyclicform. The lifecycle in the tsetse may be as short as one week with T. vivax or extend to a few weeks for T. brucei species (Aiello and Mays, 2005).

The clinical signs of the disease depend up on the species and strain of trypanosome, the vector and resistance of the affected breed animal. Trypanosomosis can be diagnosed based on either detection of the parasite by the light microscope (parasitological) or demonstration of the circulating antibody (serological) in conjunction with clinical observation (Paris et al., 1982).

In the case of. Trypanosomosis, treatment of cattle in south achefer district is generally carried out without preliminary diagnosis. It is estimated that in the district, more than $80 \%$ of all drug treatments were administered inappropriately, i.e. to. Cases perceived to be diseased with other than trypanosomosis (personal observation). In this particular situation, a rapid assessment of the present risk of tsetse transmitted trypanosomosis in a cross sectional survey is needed.

Therefore the objectives of this study is to determine the current prevalence of bovine trypanosomosis, to identify the predominant species of trypanosomes and to assess the host related risk factors of the disease in south achefer destrict.

\section{Materials AND Methods}

\subsection{Study Area}

The study was conducted from November 2013 to February 2014 in three villages selected from South Achefer district of West Gojjam Zone, Amhara Regional State, and North Western Ethiopia. South Achefer district is geographically located at $11^{\circ} 50^{\prime} \mathrm{N}$ latitude and $37^{\circ} 10^{\prime} \mathrm{E}$ longitude, $502 \mathrm{Km}$ away from Addis Ababa, the capital of Ethiopia and covers an area of $1183.05 \mathrm{Km}^{2}$. It is characterized by high plateaus, mountains and broad valleys. The elevation of the district varies from 1500-2500 m.a.s.l. The annual mean temperature for most part of the district is $23^{\circ} \mathrm{C}$ and the mean annual rain fall is $1522 \mathrm{~mm}$. The livestock populations found in the district include cattle, sheep, goats, horses, mules, donkeys and poultry. Among these animals cattle are the dominant species raised in the area. The cattle population in the district is estimated to be about 133,555 (RSA, 2008). Three villages namely Zibst, ankasha, and nunu were selected for the purpose of this study.

\subsection{Study Population}

The study was conducted on local zebu cattle. These animals were raised in different villages of south achefer district. The animals examined in this particular study were representing different Kebeles (the smallest administrative unit), sex, body conditions and age groups and reared in extensive management system.

\subsection{Study Design}

Cross sectional survey was conducted on 420 randomly selected animals to determine the prevalence of bovine trypanosomosis.

\subsection{Sample Size and Sampling Method}

Body condition score of the animals, age, coat color and sex, have recorded. The age was categorized in to three (0-3 years, 3-6 years and greater than six years) and the body condition score was grouped in to poor, medium, and good conditioned animals based on the appearance of ribs and dorsal spines applied for Zebu cattle (Nicholson and Butterworth, 1986). The desired sampling size was calculated according to the formula given by Thru field (2007).The sample size was determined based on the expected prevalence of 50\% and 95\% confidence level and 5\% precision, as result 384 samples were required. But to improve the degree of precision a total of 420 samples were taken for the study.

$$
\begin{aligned}
& \mathrm{N}=\mathrm{g} 2 \mathrm{p}(1-\mathrm{p})=\underline{1.96^{2}(0.5)(1-0.5)} \\
& \mathrm{d}^{2} \quad \text { (0.05) (0.05) }
\end{aligned}
$$

$\mathrm{N}=$ number of samples (sample size)

$\mathrm{d}=$ the desired absolute precisionat $5 \%$ 
Study on the Prevalence of Trypanosoma Species Causing Bovine Trypanosomosis in South Achefer District, Northern Ethiopia

$\mathrm{N}=384 \mathrm{p}=$ expected prevalence

\subsection{Study Methodology}

Parasitological Study

\subsubsection{Thin Blood Smear}

A small drop of blood from a micro-hematocrit capillary tube was applied to a clean slide and spread by using another clean slide at an angle of $45^{\circ}$. Then the smear dried and then fixed for 2 minutes in methyl alcohol and the thin smear was immersed within the Giemsa stain (1:10 solution) for 30 minutes. Excess stain was drained and washed by using distilled water. Then it was allowed to dry by standing up right on the rack and examined under the microscope (x100) oil immersion objective lens Office International des .Epizooties (OIE, 2008).

\subsubsection{Hematological Study}

\section{- Packed Cell Volume (PCV) Determination}

Blood samples were obtained by puncturing the marginal ear vein with a lancet and collected directly into apair of heparin is capillary tubes. Then the capillary tubes were sealed at one end with crystal seal. The capillary tubes were placed in micro-hematocrit centrifuge and were allowed to centrifuge at 12,000 revolutions per minute (rpm) for 5 minutes. After centrifugation, the capillary tubes were placed in a haematocritreader. The length of the packed red blood cells column was expressed as a percentage of the total volume of blood. Animals with packed cell volume less than $24 \%$ were considered to be anaemic office International des. Epizootie (OIE, 2008).

\section{- Buffy Coat Technique}

Heparinised microhaematocrit capillary tubes, containing blood samples were centrifuged for $5 \mathrm{~min}$ at $12,000 \mathrm{rpm}$. After the centrifugation, trypanosomes were usually found in or just above the buffy coat layer. The capillary tube cut using a diamond tipped pen $1 \mathrm{~mm}$ below the buffy coat to include the upper most layers of the red blood cells and $3 \mathrm{~mm}$ above to include the plasma. The content of the capillary tube was covered with cover slip. The slide was examined under $\mathrm{x} 40$ objective and $\mathrm{x} 10$ eye piece for movement of parasite (Paris et al 1982). Trypanosome species were identified according to their morphological descriptions on Giemsa stained blood film aswell as movement in wet film preparations provided by (Radostitis et al 2007).

\section{Statistical Analyses}

\subsection{Data Management and Analysis}

Raw data generated for this study was stored in Microsoft Excel and the prevalence of bovine trypanosomosis in different age, sexes body condition, coat color and PCV were analyzed by using STATA version 11.0; chi-square was used to compare the prevalence of trypanosome infection in different variables and to determine association between variables and the disease. Odds ratios were used to assess the association of trypanosomosis and observed clinical signs in sampled animals. In all cases differences between parameter were tested for significance at probability levels of 0.05 .

\section{RESUltS AND DISCUSSION}

The present study indicated that trypanosomosis is still of much concern and Represents a major obstacle to cattle production in south achefer district of Amhara region, northwest Ethiopia. The parasitological examination revealed a prevalence of $6.19 \%$ for bovine trypanosomosis with $T$. vivax and $T$. congolense being the pathogenic trypanosome identified during the study period (Table 1).

Table1. Prevalence of trypanosome infection in the villages

\begin{tabular}{|c|c|c|c|c|c|}
\hline Name of the village & No cattle examined & No Positive & Prevalence (\%) & $\boldsymbol{\chi} \mathbf{2}$ & p \\
\hline Ankasha & 168 & 10 & 5.95 & \multirow{2}{*}{0.57} & \multirow{3}{*}{0.75} \\
Zibst & 168 & 12 & 7.14 & \\
Nunu & 84 & 4 & 4.76 & & \\
\hline Overall & 420 & 26 & 6.19 & & \\
\hline
\end{tabular}

Of the 420 cattle examined, $26(6.19 \%)$ animals were found infected with different trypanosome species. This finding is in agreement with a similar research conducted in Ethiopia; $7.81 \%$ in 
womberma district by( Bishaw, et al.,2012), 5.85\% in Diga District, Western Ethiopia by( Dinsaet al.,2013). Prevalence of Trypanosomosis ranging from 4.0\%-9.60\% due to T. vivax in highland district areas bordering Lake Tana was also documented (Sinshaw et al .,2006). This similarity in prevalence might be due to the presence of similar agro-ecological conditions. However the result of the current study is very low when compared to the reportsmade by (Abiy 2002) in Goro district of Southwest Ethiopia (19\%) and by (Feyissa et al.,2011) in Humbo District, Southern Ethiopia (14.2\%). The relatively low prevalence found in this study may be partly attributed to the frequent use of chemotherapeutic drugs, an increase in agricultural investment and decreased tsetse challenge in the area. On the other hand the present finding is higher than the prevalence $(2.66 \%)$ reported from five tsetse free villages of Tselemty district in Tigray regional state (Tadesse et al., 2011).Trypanosome was observed in all the villages considered in this study, namely Zibist ,Ankashamunget and Nunu villages. Although there was prevalence difference of trypanosome infections in villages, the prevalence difference was not statistically significant $(\mathrm{P}>0.05)$. Two species of trypanosomes were identified in this study: $T$ vivax and T.congolense, T.vivax being the most predominant species (20 out of 26) (Table 2). This finding is in agreement with previous observations in tsetse free areas of the country (Cherenet et al., 2006 and Tadese et al., 2011). The dominancy of T. vivax over the other species in the present and the previous studies is most likely associated with its ability to be transmitted both cyclically by tsetse flies and mechanically by biting flies. In contrast to the present finding, several studies carried out in tsetse infested areas of the country have reported T.congolenseas the predominant species (Dagnachew et al., 2005), (Bekele et al., 2008) and (Bitewet al., 2011). The predominance of $T$. congolense infection in cattle may be due to the high number of serodems of $T$. congolense as compared to T. vivax and the development of better immune response to T. vivax by the infected animal (Leak, 1999)

Table2. Trypanosoms spp. identified in the villages expressed as proportion $(n=26)$

\begin{tabular}{|c|c|c|}
\hline \multirow{2}{*}{ Name of the village } & \multicolumn{2}{|c|}{ № Trypanosome spp (prevalence \%) } \\
\cline { 2 - 3 } & T.vivax & T.congolense \\
\hline Zibst & $9(75 \%)$ & $3(25 \%)$ \\
\hline Ankasha & $7(70 \%)$ & $3(30 \%)$ \\
\hline Nunu & $4(100 \%)$ & $0(0 \%)$ \\
\hline overall & $20(76.9 \%)$ & $6(23.1 \%)$ \\
\hline
\end{tabular}

Chi-square analysis of the prevalence of trypanosome infection with the sex and age of the study animals showed no significant association with either of these factors $(P>0.05)$. This result is in agreement with what were reported previously (Tadess et al., 2011) and (Bitew et al., 2011).This might be due to the fact that both sexes have virtually similar exposure to biting flies in grazing areas Similarly the prevalence of trypanosome in different age groups showed no statistically significant difference in the present study. This finding is in line with the result of the previous works by (Sinshaw, 2004), (Tadess et al., 2011., Bitew et al. (2011) and (Denbarega et al.2012).This might be due to the fact that in the present study all the animals sampled were above one year of age, so that the study animals had equal chance of getting contact with the vectors while traveling long distances for grazing as well as harvesting of crops.

In the present study, the prevalence of trypanosome infection was shown to be significantly associated $(\mathrm{P}<0.05)$ with BCS. The prevalence was higher in poorly conditioned animals $(12.33 \%)$ than in those with medium $(6.35 \%)$ or good $(4.07 \%)$ BCS. The odds of trypanosome infection among animals with poor BCS was 3.3 times higher than that of animals with good BCS (Table 3). However it would be difficult to conclude either poor body condition predispose to trypanosome infection or trypanosome infection cause loss of body condition based on such cross-sectional study (Dohoo et al., 2003), and it should be verified by using a longitudinal study designs. This finding is consistent with the observations of (Bitewet al., 2011). It has been stated that loss of body condition and progressive emaciation are the characteristic signs of trypanosomosis (Urquhart et al., 1996)Comparison conducted between the different skin colors of cattle indicated that higher prevalence was observed in cattle's having black skin color (11.57\%) followed by red $(4.86 \%)$ and white(3.23\%) skin color. Tsetse flies by nature are attracted toward a black color, so in animals having black skin color there is high prevalence of trypanosomosis recorded. Table (3) 
Study on the Prevalence of Trypanosoma Species Causing Bovine Trypanosomosis in South Achefer District, Northern Ethiopia

Table3. Analysis of the prevalence of trypanosome infection with age, and sex of the body :-condition and color animals

\begin{tabular}{|c|c|c|c|c|c|c|}
\hline \multicolumn{2}{|c|}{ Risk Factors } & No cattle examined & No Positive & Prevalence $(\%)$ & OR & P-value \\
\hline \multirow{2}{*}{ sex } & Female & 168 & 10 & 5.95 & 1 & \\
\cline { 2 - 7 } & Male & 252 & 16 & 6.35 & 1.07 & 0.869 \\
\hline \multirow{3}{*}{ Age } & $4-6 y r s$ & 227 & 13 & 5.73 & 1 & \\
\cline { 2 - 8 } & $>$ 6yrs & 67 & 4 & 5.97 & 1.20 & \\
\cline { 2 - 8 } & $1-3 y r s$ & 126 & 9 & 7.14 & 1.34 & 0.867 \\
\hline \multirow{3}{*}{ BCS } & Good & 221 & 9 & 6.07 & 1 & \\
\cline { 2 - 8 } & Medium & 126 & 9 & 12.33 & 3.3 & 0.04 \\
\cline { 2 - 8 } & Poor & 73 & 5 & 3.23 & 1 & \\
\hline
\end{tabular}

By taking the $\mathrm{PCV} \geq 24 \%$ as a normal (OIE, 2008) $16 \%$ of the non-infected animals and $34.61 \%$ of infected animals were found to be anemic. A significant reduction in PCV was observed in the trypanosome infected animals signifying anemia to be one of the important consequence of infection. The overall mean PCV of the study animals was 27.32 \pm 2.67 (range, 17-36) An assessment of the difference between mean PCV value of parasitemic and aparasitemic cattle was found to be $25.77 \pm 0.85$ and $27.42 \pm 0.02$ respectively and there was statistically significant difference between both groups $(\mathrm{P}<0.05)$. (Table 4).This result agrees with the report of other studies of bovine trypanosomosis in the country (Dagnachew et al., 2005), (Sinshaw et al., 2006), (Bitewet al., 2011) and (Tadesseet al., 2011).

In the present study the difference between the mean PCV of infected and non infected animals was not that much higher that is probably due to the farmer's habit of treating their animals (parasitemic or aparasitemic) with tripanocidal drugs with unknown dose. In addition to this animals in these areas had access to adequate nutrition due to the availability of sufficient pasture compared to animals found in other areas. These my influence the negative effect of trpanosoma parasite on the PCV value of infected animals. On the other hand, the herd average PCV is affected by Factors Other than Trypanosomosis (CONNER, R.J., 1994). These confounding factors are not always identifiable but they are likely to affect both trypanosomosis Positive and negative animals.

Table4. Association of the mean PCV of cattle with trypanosome infection

\begin{tabular}{|c|c|c|c|c|c|}
\hline Condition & $\begin{array}{c}\text { Mean PCV } \\
(\%) \pm S D\end{array}$ & $95 \%$ CI & $\begin{array}{c}\text { № examined } \\
(\mathrm{PCV}<24 \%)\end{array}$ & $\begin{array}{c}\text { №Examined } \\
(\mathrm{PCV} \geq 24 \%)\end{array}$ & p-value \\
\hline Infected & $25.77 \pm 0.85$ & $24.089-27.45$ & $26(34.6 \%)$ & $17(65.4 \%)$ & 0.019 \\
\hline Non infected & $27.42 \pm 0.02$ & $27.0-27.80$ & $394(16 \%)$ & $348(88.3 \%)$ & \\
\hline Total & $27.32 \pm 0.197$ & $26.93-27.71$ & $72(17.14 \%)$ & $348(82.86)$ & \\
\hline
\end{tabular}

\section{CONCLUSION AND RECOMMENDATION}

Trypanosomosis is an important disease and a potential threat affecting health and productivity of cattle as result the present study also indicates the significance of the disease with a prevalence of $6.19 \%$ of bovine trypanosomosis in south achefer district of Amhara region northwest Ethiopia. The result revealed that $\mathrm{T}$. vivax was the most prevalent species in the study area and the infection significantly reduced the PCV values and body condition. Consequently the disease has significant effect on cattle productivity and agricultural activities which need an integrated control of the parasite and the vectors.

Based on the conclusion, the following recommendations are forwarded

Strategic control of bovine trypanosomosis including vector control should be strengthened to improve livestock production and agricultural development in the area.

Attempt should be made to expand government and private veterinary services to serve the community properly.

Further surveys and studies should be conducted and appropriate, feasible control of trypanosomosis and/or. Vector should be implemented. 
Study on the Prevalence of Trypanosoma Species Causing Bovine Trypanosomosis in South Achefer District, Northern Ethiopia

Educating animal owners on the problems of trypanosomosis infection and on its control measure is more essential.

\section{REFERENCES}

[1] Abiy,M.(2002):Prevalence Of bovine trypanosomosis in Goroworeda, southwest Ethiopia.DVM Thesis. Addis Ababa University, DebreZeit, Ethiopia

[2] Aiello,E.,Mays,A.(1998):Tsetse transmitted Trypanosomosis. In:Merck Veterinary Manual, eighth edition. Merck and co., Inc.

[3] Begna.F.,Abebe,S and Bekele,M.(2011): Bovine Trypanosomosis in Selected Villages of Humbo District, Southern Ethiopia

[4] Bekele J.,Asmare,K.,Abebe,G.(2008): Evaluation of Deltamethrin application in the control of tsetse and trypanosomosis in the Southern rift valley (STEP) area of.Ethiop. Vet. J., 12(1): 1-7.

[5] Bishaw1,y.,Temesgen2,W.,Yideg3,N.and Alemu2,S.(2012):Prevalence of bovinetrypanosomosis in Wemberma district of West Gojjam zone, North West Ethiopia. Vet J., 2012, 16 (2), 41-48

[6] Bitew.M.,Amediey,Y.,Abebe,A.and Tolosa,T.(2011):Prevalence of bovine trypanosomosis in selected areas of JabiTehenan district, West Gojam of Amhara regional state,NorthwesternEthiopia. Afr. J. Agric. Res. 6-1:140-144

[7] Budd,L.(1999):Tsetse and Trypanosomosis research from 1980 vol.2:Economic analysis DFID commissioned report Aylesford.kent.Pp.123.

[8] Cherenet,T.,Sani,R.A.,Speybroeck,N.,Panandam,J.M.,Nadzr,S.,V.and Bossche,P.(2006):A comparative longitudinal study of bovine trypanosomiasis in tsetse-free And tsetse-infested zones of the Amhara Region, northwest Ethiopia. Veterinary Parasitology, 140, 251-258.

[9] CONNERR,J.(1994):Improving draught animal management with strategic chemotherapeutic control of trypanosomosis. In: Workshop of the animal traction network for Eastern and Southern Africa, "Improvinganimal traction technology", Lusaka, Zambia, 18-23 Jan. 1992.

[10] Dagnachew,S.,Sangwan,A.K.,Abebe,G.(2005):Epidemiology of Bovine Trypanosomosis in the Abay (Blue Nile) Basine Areas of North West Ethiopia. Revue.Elevl. Med. Vet .Pays trop

[11] Denbarga Y.,Ando,O.,Abebe R.(2012):Trypanosoma Species Causing Bovine Trypanosomosis in South Achefer District, Northern Ethiopia. J. Vet. Adv. 2(2):108-113.

[12] Dinsa1,B.,Yohannes1,M.,Degefu1,H.and Woyesa2,M.(2013):Cross-sectional study of bovine trypanosomosis and major clinical signs observed in Diga District, Western Ethiopia

[13] Dohoo,I.,Martin,W.,Stryhn,H.(2003):Veterinary Epidemiologic Research AVC inc.,Charlottetown, price Edwards island, Canada. P 145 Southern Africa, "Improving animal traction technology", Lusaka, Zambia, 18-23 Jan. 1992.

[14] Getachew A.(2005):Trypanosomosis in Ethiopia, Addis Ababa University, Faculty

[15] Hanszessin,K. and clauson, P.H.(2003):Application of field methods to assess isometamedium resistance in cattle in western Ethiopia . Acta Ttropica.90:163-170

[16] Langridge,W.P.(1976):A tsetse and trypanosomiasis survey of Ethiopia. UK Ministry of oversea department UK.Pp.1-40

[17] Leak.S.A.(1999): Tsetse Biology and Ecology: Their role in the Epidemiology of Trypanosomosis. CAB International, Nairobi, Kenya.Pp.568.

[18] Paries,J.,Murray,M.,Mcoimba,F.(1982):A comparative evaluation of the parasitological techniques currently available for the diagnosis of African animal trypanosomosis in cattle. Acta. Tropia.39:307-316.

[19] RSA.(2008):Amhara Bureau of Agricultural and rural development.

[20] Seifert,S.H.H.(1996):Tropical animal health; second edition, Dordrech: Kluwer Academic

[21] Sinshaw,A.,Abebe,G.,Desquesnes,M.,Oni,W.(2006):Biting flies and Trypanosoma

[22] Tadesse,A.,Hadgu,E.,Mekbib,B.,Abebe,R.,Mekuria,S.(2011):Mechanically transmitted bovine trypanosomosis in Tselemty Woreda, Western Tigray, Northern Ethiopia. Agric. J. 6 (1):10-13.

[23] Torr,S.J.,Wilson,P.J.,Schofield,S.,Mangwiro,T.N.C.,Akber,S.,White,B.N.(2001):Application of DNA markers to identify the individual-specific host of tsetse feeding On cattle. Med. Vet. Entomol., 15, 78-86

[24] Tsetse and trypanosomiasis prevention and control strategies. Amharic Version,October (2004):Paper presented on Farming Tsetse Controlled Areas (FITCA) Ethiopia. FinalWorkShop, December, 27- 28, 2004.Adama, Ethiopia Unpublished Work Shop Proceedings

[25] Uilenberg,G.(1998):Afield guide for diagnosis, treatment and prevention of African animal trypanosomosis ,FAO Rome.Pp.43-89 
Study on the Prevalence of Trypanosoma Species Causing Bovine Trypanosomosis in South Achefer District, Northern Ethiopia

[26] Vale,G.A.(1993):Development of baits for tsetse flies (Diptera:Glossinidae) in Zimbabwe. J.Med. Entomol., 30: 831- 842

Citation: Endalew Debas, Gedamu Mequannt, "Study on the Prevalence of Trypanosoma Species Causing Bovine Trypanosomosis in South Achefer District, Northern Ethiopia" International Journal of Research Studies In Biosciences (IJRSB), Vol. 7, no. 9, pp. 37-43, 2019. http://Dx.Doi.org/10.20431/2349-0365.0709004

Copyright: () 2019 Authors. This is an open-access article distributed under the terms of the Creative Commons Attribution License, which permits unrestricted use, distribution, and reproduction in any medium, provided the original author and source are credited. 